\title{
Potensi dan Tantangan Pengembangan Sektor Unggulan di Kalimantan Barat
}

\author{
Dinarjad Achmad* \\ UniversitasTanjungpura
}

\begin{abstract}
The primary objective of this study was to analyze the potential and challenges of superior sector development in West Kalimantan. Superior sectors here interpreted as a sector that produces goods that can be exported. Descriptive method and time series data for 7 years (2007-2013) was used as the tools and materials to perform the analysis. The results showed that the based on of natural resources (land, water area and the river, fill the earth) and geography, West Kalimantan have a greater potential for superior sector development, but there are several challenges to the development potential of the superior sector, including: (1) resource human (HR) is still weak. (2) Infrastructure (electricity, gas and water supply, road and port export) are limited. (3) Marketing and networking is still weak.
\end{abstract}

\section{Keyword: Potential, Challenges, Superior Sector}

\section{PENDAHULUAN}

Kalimantan Barat (Kalbar) merupakan salah satu dari dua Provinsi di Pulau Kalimantan yang berbatasan langsung dengan Malaysia, tepatnya dengan Negara Bagian Sarawak mempunyai luas wilayah sebesar $146.807 \mathrm{~km}^{2}$ (7,53 persen dari luas Indonesia atau 1,13 kali luas Pulau Jawa). Berarti Kalimantan Barat menjadi Provinsi terluas keempat setelah Irian Jaya mencapai $319.036 \mathrm{~km}^{2}$ (sebelum pemekaran), Kalimantan Timur mencapai $204.534 \mathrm{~km}^{2}$ dan Kalimantan Tengah mencapai $153.564 \mathrm{~km}^{2}$. Saat ini Kalimantan Barat terbagi menjadi 14 Kabupaten/Kota yang terdiri dari 12 kabupaten : Mempawah, Sambas, Ketapang, Sanggau, Sintang, Kapuas Hulu, Bengkayang, Melawi, Kayong Utara, Sekadau, Landak, Kubu Raya, dan 2 kota yaitu : Pontianak dan Singkawang.

Dari $14 \mathrm{Kab} /$ kota tersebut, terdapat tiga kabupaten yang paling luas wilayahnya yaitu Ketapang mencapai $31.240,74 \mathrm{~km}^{2}(21,28 \%$ dari luas provinsi), Kapuas Hulu mencapai $29.842 \mathrm{~km}^{2}\left(20,33 \%\right.$ dari luas provinsi), dan Sintang mencapai $21.635 \mathrm{~km}^{2}$ $(14,74 \%$ dari luas provinsi). Sejak tahun 2014 perekonomian Kalimantan Baratdidominasi oleh sektor perdagangan, hotel dan restoran.Kontribusi ketiga sektor ini

Jl.Prof.Dr.H.HadariNawawi, Pontianak, Kodepos $\quad 78124 . \quad$ HP: $\quad 08125617511 . \quad$ e-mail :dinarjad_fe@yahoo.com 
mencapai $23,40 \%$, lebih besar dari sektor pertanian 21,95\%. Telah terjadi pergeseran sektor dimana ditahun lalu sektor pertanian tetap menjadi sektor pemimpin dalam perekonomian Kalimantan Barat (lihat Tabel 1). Kedepan nampaknya sektor pertanian terus dapat dikembangkan menjadi produk untuk kebutuhan domestik dan untuk kebutuhan ekspor, terkait dengan lahan yang dimiliki belum dimanfaatkan secara optimal atau masih banyak lahan tidur (non produktif) yang dapat diberdayakan untuk menghasilkan produk ekspor.

Tabel 1. Kontribusi Sektoral PDRB Provinsi Kalimantan BaratTahun 2008 - 2014 (\%)

\begin{tabular}{|c|c|c|c|c|c|c|c|}
\hline Lapangan Usaha & 2008 & 2009 & 2010 & 2011 & 2012 & 2013 & 2014 \\
\hline 1. Pertanian & 26,12 & 25,71 & 25,07 & 25,05 & 24,01 & 23,08 & 21,95 \\
\hline 2. Pertambangan dan Penggalian & 1,87 & 1,93 & 1,99 & 2,03 & 2 & 2,1 & 2 \\
\hline 3. Industri Pengolahan & 19,49 & 18,96 & 18,41 & 17,98 & 17,01 & 16,26 & 15,52 \\
\hline 4. Listrik,Gas dan Air Bersih & 0,54 & 0,52 & 0,52 & 0,49 & 0,47 & 0,47 & 0,46 \\
\hline 5. Bangunan & 8,51 & 8,86 & 9,23 & 9,96 & 10,8 & 11,47 & 12,49 \\
\hline $\begin{array}{l}\text { 6. Perdagangan, Restoran dan } \\
\text { Hotel }\end{array}$ & 22,43 & 22,34 & 22,75 & 22,57 & 22,73 & 23,02 & 23,40 \\
\hline $\begin{array}{l}\text { 7. Pengangkutan dan } \\
\text { Komunikasi }\end{array}$ & 6,76 & 7,12 & 7,33 & 7,40 & 7,34 & 7,36 & 7,49 \\
\hline $\begin{array}{l}\text { 8. Keuangan,Persewaan } \\
\text { Bangunan dan Jasa } \\
\text { Perusahaan }\end{array}$ & 4,85 & 4,83 & 4,74 & 4,81 & 4,84 & 4,86 & 5 \\
\hline 9. Jasa-Jasa & 9,42 & 9,73 & 9,95 & 9,71 & 10,80 & 11,48 & 11,69 \\
\hline
\end{tabular}

Sumber: BPS Kalbar

Dalam era otonomi, perhatian para ekonom terhadap laju pertumbuhan ekonomi daerah semakin meningkat, Arsyad dan Blakley dalam Kuncoro (2004). Hal ini cukup logis, karena dalam era otonomi berbagai daerah baik Kabupaten/Kota maupun Provinsi bersaing untuk menciptakan laju pertumbuhan ekonomi yang tinggi guna meningkatkan kemakmuran masyarakatnya. Tabel 2 menyajikan data laju pertumbuhan ekonomi selama 7 tahun (2007 - 2013) di setiap kabupaten/kota di Kalimantan Barat. Terlihat laju pertumbuhan ekonomi di Kalimantan Barat selama 7 tahun (2007 - 2013) rata-rata mencapai $5,48 \%$ per tahun.

Laju pertumbuhan ekonomi paling tinggi diraih oleh Kabupaten Ketapang ratarata mencapai $6,59 \%$ per tahun, berada pada posisi di atas rata-rata laju pertumbuhan ekonomi Provinsi Kalimantan Barat, Secara rinci laju pertumbuhan ekonomi berbagai kabupaten/kota diProvinsi Kalimantan Barat dapat dilihat pada tabel 2 sebagai berikut : 
Tabel 2. Laju Pertumbuhan EkonomiKab/Kota Di Kalimantan Barat Selama 7 Tahun (2007-2013)Atas Dasar Harga Konstan

\begin{tabular}{clcccccccc}
\hline No & KAB/KOTA & \multicolumn{9}{c}{ Tahun (dalam persen) } & \multirow{2}{*}{ Rata-rata } \\
\cline { 3 - 9 } & & $\mathbf{2 0 0 7}$ & $\mathbf{2 0 0 8}$ & $\mathbf{2 0 0 9}$ & $\mathbf{2 0 1 0}$ & $\mathbf{2 0 1 1}$ & $\mathbf{2 0 1 2}$ & $\mathbf{2 0 1 3}$ & \\
\hline 1. & Sambas & 5,38 & 5,51 & 5,43 & 5,79 & 5,80 & 5,88 & 5,99 & 5,68 \\
2 & Bengkayang & 6,12 & 5,57 & 4,50 & 4,63 & 5,65 & 5,74 & 6,04 & 5,46 \\
3 & Landak & 5,13 & 4,29 & 4,71 & 5,13 & 6,90 & 6,01 & 6,21 & 5,48 \\
4 & Mempawah & 5,15 & 5,90 & 1,32 & 2,13 & 4,85 & 3,17 & 5,08 & 3,94 \\
5 & Sanggau & 5,48 & 3,49 & 5,95 & 4,15 & 4,61 & 5,92 & 6,04 & 5,09 \\
6 & Ketapang & 10,33 & 7,14 & 1,22 & 7,51 & 7,98 & 5,01 & 6,97 & 6,59 \\
7 & Sintang & 5,16 & 4,70 & 5,38 & 5,19 & 5,45 & 5,82 & 6,34 & 5,43 \\
8 & Kapuas Hulu & 5,42 & 3,35 & 3,70 & 4,44 & 4,56 & 5,61 & 6,01 & 4,73 \\
9 & Sekadau & 7,53 & 5,76 & 5,35 & 5,85 & 5,73 & 5,95 & 6,71 & 6,13 \\
10 & Melawi & 5,44 & 5,11 & 4,27 & 5,75 & 6,14 & 6,48 & 6,73 & 5,70 \\
11 & Kayong Utara & 3,72 & 5,84 & 2,78 & 5,92 & 5,93 & 6,01 & 6,00 & 5,17 \\
12 & Kubu Raya & - & 5,02 & 5,87 & 6,23 & 6,51 & 6,69 & 6,79 & 6,19 \\
13 & Kota PTK & 5,45 & 5,42 & 4,35 & 5,39 & 5,88 & 6,07 & 6,91 & 5,64 \\
14 & Kota Singkawang & 4,72 & 4,9 & 4,88 & 5,54 & 6,46 & 6,16 & 6,36 & 5,57 \\
& Kalimantan Barat & 5,77 & 5,14 & 4,27 & 5,26 & 5,89 & 5,75 & 6,29 & 5,48 \\
\hline
\end{tabular}

Sumber:BPS Kalbar

Melalui laju pertumbuhan ekonomi yang cukup tinggi, diharapkan lebih banyak tenaga kerja dapat diserap di tiap daerah dan kesejahteraan masyarakat secara bertahap dapat ditingkatkan. Sumber penentu laju pertumbuhan ekonomi daerah bila dilihat dari PDRB sisi penggunaan, dapat dilihat pada tabel 3 sebagai berikut:

Tabel 3. Kontribusi Kegiatan Ekonomi Terhadap PDRB Kalimantan Barat Tahun 2007- 2013 (Persen)

\begin{tabular}{lcccccccc}
\hline \multicolumn{1}{c}{ Kegiatan Ekonomi } & $\mathbf{2 0 0 7}$ & $\mathbf{2 0 0 8}$ & $\mathbf{2 0 0 9}$ & $\mathbf{2 0 1 0}$ & $\mathbf{2 0 1 1}$ & $\mathbf{2 0 1 2}$ & $\mathbf{2 0 1 3} *$ & Rata-rata \\
\hline $\begin{array}{l}\text { Pengeluaran Konsumsi } \\
\text { Rumah Tangga (C) }\end{array}$ & 52,18 & 55,94 & 55,66 & 55,72 & 55,50 & 56,03 & 56,83 & 55,41 \\
$\begin{array}{l}\text { Pengeluaran Konsumsi } \\
\text { LembagaNon Profit }\end{array}$ & 0,75 & 0,77 & 0,78 & 1,03 & 1,01 & 1,03 & 1,16 & 0,93 \\
$\begin{array}{l}\text { Pengeluaran Investasi } \\
\text { PMTB (I) }\end{array}$ & 27,43 & 28,13 & 28,30 & 31,03 & 32,35 & 34,50 & 34,09 & 30,83 \\
$\begin{array}{l}\text { Pengeluaran Pemerintah } \\
\text { (G) }\end{array}$ & 13,26 & 16,17 & 16,22 & 12,68 & 12,69 & 11,92 & 12,35 & 13,61 \\
Ekspor (X) & 26,24 & 30,07 & 20,96 & 13,40 & 20,96 & 14,55 & 15,21 & 20,20 \\
Impor (M) & 21,47 & 27,59 & 20,96 & 16,30 & 25,08 & 19,18 & 21,34 & 21,70 \\
TotalPDRB (Miliar Rp) & 43.54 & 49.13 & 54.28 & 86.07 & 96.73 & 106.96 & 118.62 & 79.33 \\
\hline
\end{tabular}

Sumber: BPS Kalbar

*Angka sementara

Tabel 3 jelas menunjukkan dari tahun ke tahun selama 7 tahun (2007 - 2013 ), laju pertumbuhan ekonomi Kalimantan Barat didukung oleh sisi permintaan domestik (pengeluaran konsumsi rumah tangga),rata-rata diatas 50\% sedangkan pengeluaran investasi berada pada posisi kedua $27,5 \%$ dan sektor unggulan menepati posisi ketiga 26,5\%. Apabila kebijakan indusri berhasil dikembangkan, kedepan diharapkan sektor unggulan yang dihasilkan tidak lagi dalam bentuk raw material, namun sudah dalam bentuk produk jadi yang siap pakai. Kebijakan pengembangan industri hilir ini, secara akademis lebih menguntungkan perekonomian dan lebih banyak memberikan 
manfaatdiantaranya kesempatan kerja bertambah, meningkatkan produktivitas lahan, inflasi terjaga karena sisi supply bisa dengan segera merespon sisi demand.

Pengembangan sektor unggulan di Kalimantan Barat penting dilakukan mengingatlahan untuk perkebunan hanya mencapai 1.755 .558 hektar (11,93\% dari 14,68 ribu hektar luas Kalimantan Barat), danoptimalisasi pemanfaatan lahan masih rendah karena masih ada padang semak belukar/alang-alang $(32,64 \%$ lahan yang belum dimanfaatkan). Sebagian besar (41,61\%) tanah di Provinsi Kalimantan Barat ditumbuhi oleh hutan, areal hutan terluas berada di Kabupaten Kapuas Hulu mencapai 1.960.578 hektar yang berfungsi sebagai paru-paru dunia dan areal padang semak belukar/alangalang terluas ada di Kabupaten Ketapang mencapai 1.374.146 hektar. Areal untuk pemungkiman hanya 0,83 persen dan areal pemungkiman yang terluas berada di 3 Kabupaten yaitu Ketapang, Sintang, dan Kapuas Hulu.

\section{TINJAUAN PUSTAKA}

Peningkatan ekspor akan memberikan dampak berganda (multiplier effect) pada perekonomian daerah (Sjafrizal,2008; Barry,2009; Schmitt,2001; Brock,1991) dan model basis ekspor dapat menjadi tulang punggung perekonomian daerah, karena memiliki keuntungan kompetitif tinggi (Sjafrizal, 2008;Nishiyama \&Yamaguci,2009).Perekonomian yang dominan menggunakan sumberdaya lokal, termasuk tenaga kerja dan bahan baku untuk ekspor akan menghasilkan kekayaan daerah dan menciptakan kesejahteraan(Arsyad, 1999).Hal ini menunjukkan bahwa kemajuan perekonomian suatu daerah berhubungan langsung dengan permintaan barang/jasa dari luar daerah

Semakin banyak produk yang dihasilkan untuk ekspor diharapkan mampu menciptakan dan memperbesar laju pertumbuhan ekonomi, yaitu laju pertumbuhan ekonomi yang mampu mendorong peningkatan kesempatan kerja(Smith dalam Pressman,2002), Selanjutnya menurut Mun dalam Pressman (2002), cara yang wajar untuk meningkatkan kemakmuran dan kekayaan adalah dengan perdagangan luar negeri, dimana pelaku ekonomi harus memperhatikan aturan yaitu menjual lebih banyak ke pihak luar daerah dan pihak asing, artinya ekspor harus lebih besar dari impor.

Melalui pendekatan interregional income model yang dikemukakan oleh Richardson (1978) dalam Sjafrizal (2008) ekspor diasumsikan sebagai faktor yang berada dalam sistem yang ditentukan oleh perkembangan kegiatan perdagangan antar wilayah dan kegiatan perdagangan antar daerah tersebut dibagi atas barang konsumsi dan barang modal. Selain itu agar lebih realistis unsur pemerintah juga dimasukkan, ditampilkan dalam bentuk penerimaan dan pengeluaran pemerintah daerah serta kegiatan investasi sesuai dengan prinsip teori ekonomi Keynes. Mengikuti logika Keynes model pertumbuhan interregional sederhana dapat dijelaskan melalui konsep bahwa pendapatan regional (PDRB) tahun tertentu akan dialokasikan untuk membiayai kebutuhan konsumsi 
masyarakat, investasi swasta, investasi pemerintah, dan untuk membiayai pembuatan barang ekspor serta untuk membeli barang impor yang dibutuhkan oleh setiap daerah termasuk Provinsi Kalimantan Barat.

Melalui pendekatan Keynes ini, dengan asumsi bahwa pengeluaran pada tahun tertentu menjadi pendapatan bagi semua pelaku dalam perekonomian pada tahun berikutnya, maka ekspor yang dilakukan oleh para eksportir di Kalimantan Barat merupakan variabel yang unik dan dapat dijadikan sebagai variabel eksogenyang mampu mempengaruhi variabel endogenseperti laju pertumbuhan ekonomi dan kesempatan kerja.

Beberapa alasan mengapa variabel ekspor dipandang sebagai variabel yang unik sehingga perlu di setting kedalam sebuah model konseptual sebagai exogenvariable dan variabel laju pertumbuhan ekonomi dan kesempatan kerja menjadi sumber yang sangat penting sebagai strategi untuk membuat kebijakan dalam pembangunan ekonomi guna menaikkan tingkat kesejahteraan masyarakat di Provinsi Kalimantan Barat.

Alasan pertama adalah jika dilihat dari sisi ekonomi Islam, sejak zaman Rasul bangsa-bangsa di dunia ini telah melakukan perdagangan antar negara (Karim,2010). Hingga saat ini perdagangan antar negara tersebut tetap ada, dan menjadi meng-global ke seluruh wilayah dunia, saat ini lebih populer disebut dengan era globalisasi perdagangan. Alasan keduaadalah meskipun negara sedang berkembang dan negara miskin di dunia mendapatkan pengalaman bahwa perdagangan antar negara di era globalisasi memberikan dampak negatif bagi mereka, namun Indonesia harus tetap melakukan perdagangan antar negara (ekspor dan impor) karena ekspor dapat mendorong peningkatan laju pertumbuhan ekonomi,telah dibuktikan oleh berbagai negara yang melakukan ekspor-impor seperti Jepang, Korea, Singapura, Malaysia dan Hongkong. Sebagai bukti yang jelas adalah laju pertumbuhan ekonomi di Hongkong lebih tinggi dan bahkan dapat melampaui laju pertumbuhan ekonomi Cina daratan.Alasan ketigaadalahjatuhnya Uni Soviet dan komunis Blok Timur sebagai bukti bahwa sistem ekonomi tertutup (closed economics system) tidak mampu mengatur urusan ekonomi umat manusia secara lebih memuaskan dibandingkan dengan sistem ekonomi terbuka (open economics system), karena ekonomi terbuka atau ekonomi pasar mampu mendistribusikan barang yang dibutuhkan oleh berbagai negara di seluruh dunia, dan menurutHeilbroner (1989) dalam Skousen (2009) bahwa perdagangan luar negeri (ekspor) dapat menciptakan kesejahteraan masyarakat. Berdasarkan penjelasan tersebut, perdagangan (ekspor) dianggap sebagai variabel unik karena dipandang sebagai kunci pendorong peningkatan laju pertumbuhan dalam jangka panjang guna mencapai kesejahteraan masyarakat.

\section{METODE PENELITIAN}

Tulisan ini bertujuan ingin mendeskripsikan potensi dan tantangan daerah Kalimantan Barat dalam pengembangan sektor unggulan, oleh sebab itu metode yang tepat 
digunakan untuk menjawab tujuan tersebut adalah metode penelitian deskriptif, yaitu suatu metode yang mengungkapkan apa adanya yang ditemui dilapangan (Emory,1996 ; Sugiyono,2009). Jenis data yang digunakan adalah data time series yaitu data yang disusun secara historis dari waktu ke waktu selama 7 tahun (2007-2013).Adapun sumber data yang digunakan adalah data sekunder publikasi dari Badan Pusat Statistik (BPS) Kalimantan Barat.

Alat yang digunakan untuk menjawab tujuan penelitian ini adalah analilis statistik deskriptif yaitu dengan membandingkan nilai rata-rata, nilai maksimum dan nilai minimum dari setiap variabel yang diteliti dan kemudian melakukan interpretasi ekonomi dari berbagai temuan tersebut.

\section{POTENSI DAN TANTANGAN PENGEMBANGAN SEKTOR UNGGULAN DI KALIMANTAN BARAT}

Termonologi potensi ekspor dalam tulisan ini, dimaknai sebagai suatu sistem produksi yang masih berpeluang menghasilkan produk untuk di ekspor (antar pulau dan luar negeri). Terkait dengan makna tersebut maka kondisi kekayaan sumberdaya alam (SDA), sumberdaya manusia (SDM), dan sumberdaya pendukung lainnya yang tersedia dan belum termanfaatkan secara maksimal (non produktif) di Kalimantan Barat menjadi potensi yang dapat diberdayakan secara optimal guna mendukung rencana Kementerian Perdagangan RI untuk mewujudkan peran sektor unggulan dalam mendorong peningkatan pertumbuhan ekonomi melalui program pengembangan ekspor nasional, termasuk pengembangan ekspor Kalimantan Barat ke depan. Identifikasi besarnya potensi pengembangan sektor unggulan dilihat dari potensi sumber daya alam adalah sebagai berikut:

Tabel 4. Potensi Sumber Daya Alam Untuk Pengembangan Sektor Unggulan di Kalimantan Barat

\begin{tabular}{|c|c|c|c|}
\hline No & Kondisi & Dukungan & Potensi \\
\hline 1 & $\begin{array}{l}\text { Luas lahan yang belum dimanfaatkan } \\
\text { untuk pengembangan produk ekspor } \\
\text { hasil tanaman pangan dan perkebunan }\end{array}$ & $\begin{array}{l}\text { Lahan semak belukar } \\
32,64 \%\end{array}$ & $\begin{array}{l}\text { Besar dapat diberdayakan } \\
\text { menjadi lahan produktip } \\
\text { untuk pengembangan sector } \\
\text { unggulan daerah }\end{array}$ \\
\hline 2 & $\begin{array}{l}\text { Luas Perairan dan Sungai yang dapat } \\
\text { dimanfaatkan untuk pengembangan } \\
\text { produk ekspor hasil perikanan }\end{array}$ & $\begin{array}{l}\text { Julukan Provinsi } \\
\text { "Seribu Sungai”Sungai } \\
\text { Kapuas .terpanjang di } \\
\text { Indonesia (1.086 km), } \\
\text { yang } \\
\text { mana sepanjang } 942 \\
\text { km dapat dilayari. } \\
\text { Sungai besar lainnya } \\
\text { Melawi ( dapat dilayari } \\
471 \mathrm{~km}) \text {, Sungai } \\
\text { Pawan (197 km), } \\
\text { SungaiKendawangan } \\
\text { (128 km), Sungai Jelai } \\
\text { (135km), Sungai } \\
\text { Sekadau (117 km), } \\
\text { SungaiSambas (233 }\end{array}$ & $\begin{array}{l}\text { Besar untuk diberdayakan } \\
\text { menjadi sungai dan danau } \\
\text { yang produktip untuk } \\
\text { pengembangan sector } \\
\text { unggulan daerah. }\end{array}$ \\
\hline
\end{tabular}


3 Isi bumi yang belum ditemukan dan sudah ditemukan yang dapat dimanfaatkan untuk pengembangan produk ekspor hasil sektor pertambangan

4 Banyaknya produk primer di sub sektor pertanian tanaman pangan yang diekspor saat ini dapat dimanfaatkan untuk mengembangkan ekspor disektor industri pengolahan makanan

5 Banyaknya produk primer disub sektor pertanian tanaman perkebunan yang diekspor saat ini dapat dimanfaatkan untuk mengembangkan ekspor disektor industri pengolahan berbagai jenis produk hasil perkebunan

6 Banyaknya produk primer di subsektor perikanan yang diekspor saat ini dapat dimanfaatkan untuk mengembangkan ekspor disektor industri pengolahan berbagai jenis produk hasil perikanan.

7 Banyaknya produk primer disektor pertambangan dan penggalian yang diekspor saat ini dapat dimanfaatkan untuk mengembangkan ekspor disektor industri pengolahan hasil berbagai tambang km), Sungai Landak

(178 km),Danau

Sentarum mempunyai luas117.500 hektar serta Danau Luar sekitar 5.400hektar. Kedua danau ini mempunyai potensi yang baik ternak ikan untuk ekspor

Kontribusi sektor Pertambangan dan Penggalian rata-rata baru mencapai $2 \%$

$$
0,18 \%
$$

Besar dapat mendirikan industri pertambangan yang menghasilkan barang-barang ekspor menjadi sector unggulan daerah.

Meskipun dilihat dari sumber daya alam (luas lahan, luas perairan dan sungai, isi bumi) dan geografi, Kalimantan Barat memiliki potensi lebih besar untuk pengembangan sector unggulan dimasa depan, namun tantangan untuk pengembangan potensi sector uggulan tersebut adalah (1) dukungan sumberdaya manusia (SDM) yang masih lemah. (2)dukungan infrastruktur (listrik,gas dan air bersih, jalan darat, dan pelabuhan ekspor),pemasaran, dan jaringan kerja juga masih lemah. Bukti dari dukungan sumber daya manusia dan infrastuktur tersebut masih lemah dapat dilihat pada tabel 4 dan 5 sebagai berikut: 
Tabel 5. Tantangan Pengembangan Sektor UnggulanDari Sisi Sumberdaya Manusia di Kalimantan Barat

\begin{tabular}{clll}
\hline No & Kondisi & Potensi & Dukungan \\
\hline 1 & Lama Sekolah & 6,6 tahun & Lemah \\
2 & Melek Hurup & $89,70 \%$ & Lemah \\
3 & Harapan Hidup & 70,5 tahun & Sedang \\
4 & Budaya Paternalistik & Kuat & Lemah \\
5 & Rata-pengeluaran & Rp.630,340 & Kecil \\
6 & IPM & 68,79 & Sedang \\
7 & Keahlian dan Teknologi & menengah & Sedang \\
8 & Pemasaran dan Jaringan Kerja & dasar & Lemah \\
9 & Buruh & Over Supply & Kuat \\
\hline
\end{tabular}

Tabel 6. Tantangan Pengembangan Sektor UnggulanDari Sisi Inf rastruktur di Kalimantan Barat

\begin{tabular}{clll}
\hline No & Kondisi & Potensi & Dukungan \\
\hline 1 & Lembaga keuangan bank non bank & Over Supply & Kuat \\
2 & Penanaman Modal Tetap & $27,82 \%$ & Sedang \\
& Bruto(PMTB) & Over Supply & Kuat \\
3 & Transportasi & $0,63 \%$ & Lemah \\
4 & Listrik, Gas dan Air Bersih & $7 \%$ & Sedang \\
5 & Pengangkutan dan Komunikasi & kurang & Lemah \\
6 & Jalan Darat & kurang & Lemah \\
7 & Pelabuhan ekspor & lancar & Sedang \\
8 & Pelabuhan Udara & & \\
\hline
\end{tabular}

\section{KESIMPULAN}

Berdasarkan hasil analisis data yang dilakukan, sebenarnya Kalimantan Barat memiliki potensi besar untuk pengembangan sektor unggulan, khususnya terkait dengan sumber daya alam (SDA) yang cukup besar dibandingkan dengan Provinsi lain di Indonesia. Potensi wilayah perbatasan juga seharusnya dapat dimanfaatkan secara optimal sebagai tempat memasarkan produk ekspor yang dihasilkan oleh sektor unggulan Provinsi Kalimantan Barat. Meskipun dilihat dari SDA Kalimantan Barat memiliki potensi ekspor yang besar dimasa depan, namun tantangannya untuk memberdayakan potensi tersebut, terkait dengan dukungan SDM yang 57 persen masih lemah dan dukungan infrastruktur (listrik,gas dan air bersih, jalan darat dan pelabuhan ekspor) 42,9 persen masih lemah. Oleh sebab itu agar potensi ekspor yang ada dapat dikembangkan maka kelemahan dukungan SDM dan infrastruktur harus segera diperbaiki.

Perbaikan dalam dilakukan dengan cara : (1) Menanamkan nilai-nilai mentalitas usaha yang tinggi kepada masyarakat, khususnya terhadap kaum muda agar ketika merekatelah berfungsi sebagai pelaku ekonomi lebih cenderung melihat potensi ekspor sebagai peluang untuk usaha yang dapat dimanfaatkan guna meningkatkan peran sektor unggulan mendorong perkembangan perekonomian daerah. Tindakan ini dipandang dapat mengatasi kelangkaan entrepreneur dalam pembangunan ekonomi karena kedepan dapat menaikkan jumlah generasi mendatang yang bermental entrepreneur; (2) 
Menanamkan rasa pentingnya menguasai bahasa dan teknologi informasi kepada masyarakat, khususnya terhadap kaum muda, agar ketika mereka telah berfungsi sebagai pelaku ekonomi dapat dengan mudah melakukan negoisasi dalam transaksi perdagangan antar negara; (3) Mempercepat pembangunan pelabuhan ekspor di Kalimantan Barat untuk kelancaran pengangkutan barang ke negara tujuan ekspor dan mempercepat penambahan kapasitas listrik dan air bersih untuk kelancaran proses produksi produk yang akan di ekspor serta mempercepat perbaikan kondisi jalan yang rusak untuk memperlancar pengangkutan barang dari kebun ke pabrik dan dari pabrik ke pelabuhan ekspor ; (4) Meningkatkan promosi dagang ke berbagai negara dan meningkatkan peran perwakilan Indonesia (para duta besar) diberbagai negara untuk menemukan dan meningkatkan peluang ekspor guna mendukung pengembangan sektor unggulan di berbagai daerah di Indonesia; (5) melakukan sosialisasi pada masyarakat, khususnya kaum ibu yang memandang profesi wirausaha (entrepreneur) lebih rendah dari pegawai negeri sipil (PNS) dan karyawan Bank, ketika mereka melakukan seleksi penerimaan menantu. Tindakan ini dilakukan guna menghilangkan budaya paternalistik dalam masyarakat yang dapat menghambat pembangunan ekonomi, terutama pengembangan potensi sector unggulan di berbagai daerah ; (6) instansi terkait dapat meningkatkan frekuensi sosialisasi dan implementasi program yang dapat mencerahkan pikiran masyarakat (generasi muda) dalam mengisi kehidupan diberbagai bidang ekonomi, terutama dibidang ekspor.Tindakan ini dilakukan guna memperkaya pengetahuan dan pengalaman masyarakat menangani hambatan dalam pengembangan potensi ekspor daerah.

\section{DAFTAR PUSTAKA}

Arsyad, L. (1999). Ekonomi Pembangunan. Yogyakarta: Penerbit Sekolah Tinggi Ilmu Ekonomi(STIE) YKPN.

BPS Indonesia. (2008). Produk Domestik Bruto IndonesiaKatalog BPS 930200. Jakarta : Badan Pusat Statistik.

Barry.(2009).Prospek Perdagangan Indonesia Cina dan India. Jurnal Ekonomi dan Pembangunan, VolXVII(2),ISSN 0854-526X, Akred-LIPI/P2MBI/06/2008.

Brock. (1991). Ketidakstabilan Ekspor dan Kinerja Ekonomi Dari Negara Berkembang.Journal Economi Dynamics and Control, 15,129- 147.

Coper, D.R., \& Emory,W. (1996). Metode Penelitian Bisnis. Jakarta:Penerbit Erlangga. Kuncoro, M. (2003). Metode Riset Untuk Bisnis \& Ekonomi. Jakarta: Penerbit Erlangga.

Kuncoro, M. (2006a). Ekonomi Pembangunan, Teori Masalah dan Kebijakan. Yogyakarta: UPP STIM YKPN. 
Karim. (2010). Sejarah Pemikiran Ekonomi Islam. Jakarta: Grafindo Persada.

Pressman,S. (2002). Lima Puluh Pemikir Ekonomi Dunia. Jakarta: PT.Raja Grafindo Persada.

Schmitt. (2001).Strategic Export Policy with Foreign Direct Investment and Import Substitution. Journal of Development Economic, 62.

Sjafrizal. (2008). Ekonomi Regional Teori dan Aplikasi. Padang: Baduose Media.

Mark, S. (2009). Sejarah Pemikiran Ekonomi. Jakarta: Prenada Media Group.

Sugiyono. (2009). Statistik Untuk Penelitian. Bandung: Alfabeta.

Nishiyama, H., \&Yamaguchi, M. (2009). Foreign Direct Investment,International Trade and Firm Heterogeneity.Economic modeling,27(1), 184-195. 